\title{
Adhesion molecules in breast carcinoma: a challenge to the pathologist
}

\author{
Claudia Rossetti ${ }^{1}$, Beatriz da Costa Aguiar Alves Reis ${ }^{2 *}$, Pamela de Oliveira Delgado ${ }^{3}$, Ligia Ajaime Azzalis ${ }^{4}$, \\ Virginia B. C. Junqueira ${ }^{4}$, David Feder ${ }^{5}$, Fernando Fonseca ${ }^{4}$ \\ ${ }^{1}$ Pathologist at Faculty of Medicine of ABC (FMABC), Santo André, SP, Brazil \\ ${ }^{2}$ Post-doc in genomics and researcher at FMABC, Santo André, SP, Brazil \\ ${ }^{3}$ Master in Health Sciences, FMABC and Higher Level Technician of the Clinical Analyses Laboratory FMABC, Santo André, SP, Brazil \\ ${ }^{4}$ Phd in Biochemistry and professor of Universidade Federal de São Paulo (Unifesp), São Paulo, SP, Brazil \\ ${ }^{5}$ Full professor of Biochemistry at FMABC, Santo André, SP, Brazit \\ ${ }^{6}$ Post-doc in Clinical Biochemistry and professor at FMABC, Santo André, SP, Brazil
}

\begin{abstract}
SUMmaRY
Study conducted at the clinical analysis laboratory at Faculty of Medicine of $A B C$ - FMABC

Article received: $3 / 24 / 2014$ Accepted for publication: $6 / 7 / 2014$

*Correspondence Address: Avenida Príncipe de Gales, 821 Postal Code: 09060-650 Santo André - SP bcaalves@uol.com.br

http://dx.doi.org/10.1590/1806-9282.61.01.081

The role of adhesion molecules is very important both in the activation of carcinogenesis and in the differentiation of subtypes of breast carcinoma, aiding in diagnosis, prognosis and therapeutic choice in these tumors. Therefore, understanding the functions and interrelationships among these molecules is crucial to the pathologist, who often uses these factors as a resource to differentiate tumors and further classify them according to a molecular point of view. Our goal is to describe the applicability and the difficulties encountered by the pathologist in the diagnosis of breast carcinoma, discussing the most commonly used markers of adhesion in routine analyses.
\end{abstract} Conflict of interest: none
Keywords: cell adhesion molecules, junctional adhesion molecules, breast neoplasms.

\section{INTRODUCTION}

Currently, breast cancer presents as a public health problem, given its increasing incidence in recent decades, corresponding to a major cause of death from cancer among women. Statistics indicate an increase in its frequency in both developed and developing countries. ${ }^{1}$ Nevertheless, the increasing use of screening methods such as mammography, has allowed the detection of smaller and more localized lesions. Furthermore, growing knowledge of tumor biology and the introduction of new therapeutic techniques have contributed to the decrease in mortality. The improvement of mammography, the use of more conservative surgery and the progress made by molecular genetics can be pointed out as some of the significant advances of the last decade. ${ }^{1}$

Among the advances achieved using molecular tools, we can mention a greater knowledge about the interaction of adhesion molecules with the extracellular matrix and other cells. Thus, important discoveries are being made to determine the interrelationships involved in adhesion, carcinogenesis and progression to metastasis.

Several studies have shown the relationship between the expression of adhesion markers, such as E-cadherin and P-cadherin, among other adhesion molecules, and both poor prognosis and increased metastatic potential of breast tumors. ${ }^{2,3}$

In addition to the cadherins family, other adhesion molecules have been studied aiming at understanding their role in mammary carcinogenesis in order to associate such discoveries with the development of new therapeutic targets. These molecules include the claudins, particularly claudin- 1 and -2 , whose expression in breast carcinomas has been correlated with poor prognosis and increased cell dedifferentiation capacity (epithelial-mesenchymal transition). ${ }^{4}$

We also found a significant role in matrix metalloproteinases, a group of hydrolytic enzymes produced by tumor cells that can degrade the extracellular matrix and adhesion molecules. We report here, briefly, the main actions of these molecules, providing data often fundamental to reach a conclusive diagnosis, prognosis and therapeutic choice.

\section{Cadherins}

Cadherins are a group of functionally related glycoproteins, responsible for the calcium dependent cell-to-cell adhesion mechanism. They are divided into subclasses 
E-, P-, and $\mathrm{N}$-cadherins, and are distinct with regard to immunological specificity and tissue distribution. ${ }^{5}$

E-cadherin is a transmembrane glycoprotein that mediates calcium-dependent intercellular adhesion and is particularly involved in epithelial cell to cell adhesion. ${ }^{6}$ This glycoprotein is encoded by the CDH1 gene, located on chromosome 16q22.1 and expressed by ductal epithelial cells in breast tissue. ${ }^{7}$ The absence of E-cadherin results in loss of adhesion of the cell blocks, increasing the potential for invasion, distant metastases and poor prognosis for cancer. ${ }^{8}$ Due to these characteristics, it is thought that this protein would play an important role in tumor suppression. ${ }^{9}$

Studies have shown that aberrant expression of E-cadherin is associated with the acquisition of invasiveness and more advanced stages of cancer including lung, ${ }^{10}$ prostate ${ }^{11}$ gastric, ${ }^{12}$ colorectal ${ }^{13}$ and mammary carcinoma. ${ }^{14}$

There is ample evidence of the importance of E-cadherins to inhibit tumor invasion and metastases: the metastatic potential of various cancer cell lines is inversely related to the expression of E-cadherin; high levels of E-cadherin in some tumors relate to a smaller number of metastases; blocking the expression of E-cadherin increases tumor cell motility, invasion and their metastatic potential; and finally, increased E-cadherin in breast cancer inhibits cell motility and invasion. Jiang et al. ${ }^{15}$ showed that gamma-linolenic acid (GLA) increases the expression of E-cadherin in many types of human tumor cells, including breast, lung, colon, melanoma and liver cancers.

High levels of E-cadherin are associated with an increase in cell aggregation and reduction of cell invasion in $v i$ tro. Other substances that, just as gamma linolenic acid, increase the expression of E-cadherins are: cis retinoic acid, 17 beta-estradiol, tamoxifen, relaxin and the rise in serum calcium. Even in tumors that do not express E-cadherin, GLA regulates cell adhesion mediated by desmosomes, increasing cell to cell adhesion, preventing the cells from loosening with subsequent metastasis. ${ }^{16}$

The loss of E-cadherin is possibly a transient phenomenon, allowing malignant cells to invade tissues and vascular channels. It has been shown that intralymphatic emboli in breast carcinomas express this protein strongly, suggesting that re-expression of E-cadherin occurs in circulating tumor cells, enabling the neoplastic cells to produce emboli and survive. Re-expression of E-cadherin also makes tumor cells capable of forming metastatic deposits by further facilitating cell adhesion in neoplastic cells. ${ }^{9,17}$

In addition to its important role as a prognostic factor in carcinomas, E-cadherins are also used as an aid in the identification of tumor types, especially to differen- tiate between ductal and lobular carcinomas; Qureshi et al. ${ }^{18}$ reported the loss of E-cadherin expression in $90 \%$ of the cases of invasive lobular carcinomas analyzed by them.

P-cadherin is expressed by myoepithelial cells of normal breast tissue and is aberrantly expressed in a small group of breast carcinomas; the expression of this protein is significantly correlated with tumors of high histologic grade, negative for estrogen receptors. ${ }^{2}$

The aberrant P-cadherin expression in breast carcinomas has been explained as a reflection of histogenesis from the differentiation of a precursor cell in a myoepithelial phenotype, or the acquisition of proliferative capacity by tumor cells, or due to an oncofetal phenomenon. ${ }^{10,14}$ Although not yet well explained, these mechanisms demonstrate a strong correlation between the expression of this protein, negative results for hormone receptors, tumor aggressiveness and poor prognosis. ${ }^{2,19} \mathrm{P}$-cadherins are always expressed in cells that need to divide and maintain an undifferentiated state. This is because, unlike E-cadherins, the first offers a less stable adhesion between cells, promoting cell proliferation. ${ }^{20}$ Interestingly, the expression of P-cadherin has been correlated with the deregulation of E-cadherin, ${ }^{14}$ which has a growth-suppressing role in normal epithelium. ${ }^{21}$ In mammary carcinogenesis, there are several genetic and completely distinct pathways of cancer, which may cause different types of tumors. Some arise from epithelial estrogen-dependent growth, while others, without interference from the action of estrogen receptors and expressing P-cadherin, have autonomous growth by activating an independent alternative pathway of steroid hormones, thus becoming insensitive to the effects of estrogen action and consequently to drugs that block the hormone action.

\section{Claudins}

The members of the claudin family of proteins represent the majority of the membrane proteins located exclusively in cell junctions. Claudins have a tissue-specific expression and regulate the physiological properties of cell junctions between tissues. In breast cancers, the loss of claudin expression, especially claudin- 1 (encoded by the CLDN1 gene, located on chromosome 3q28-q29) and -2 (encoded by the CLDN2 gene, located on chromosome Xq22.3-q23) consists of one of the changes that characterize the aggressive phenotype, with worse prognosis and few therapeutic options. This protein has been often interpreted as a tumor suppressor gene. ${ }^{22}$

'Claudin-low' tumors are characterized by low or absent expression of luminal differentiation markers, high probability of expression for epithelial-mesenchymal tran- 
sition markers and aspects similar to cancers derived from stem cells. Clinically, these tumors show poor prognosis, and are negative for estrogen, progesterone and c-erbB-2 receptors (triple negative). ${ }^{4}$

\section{Mucins}

Mucins are O-glycosylated proteins that participate in the mucus protective barrier on the cellular surface of different tissues, and in intracellular signaling. Overexpression, aberrant intracellular location and changes in the glycosylation of this protein have been associated with carcinomas. Mucins are classified as Muc 1 to Muc 6; aberrant expression in neoplastic cells, mainly related to Muc 1 (encoded by the Muc 1 gene, located on chromosome 1q21) and -3 (encoded by the Muc 3 gene, located on chromosome $7 \mathrm{q} 22$ ), is associated with poor prognosis, increased local recurrence rate and lymph node positivity in breast carcinomas. ${ }^{23,24}$

Aberrant expression of Muc 1 is reported in invasive micropapillary carcinomas, an infrequent and very aggressive histological type of breast cancer. The aberrant pattern of Muc 1 expression in this histological type is described by several authors ${ }^{25-27}$ who, contrary to expectations, found the protein by immunohistochemistry at the basal edge of the neoplastic blocks. This represents a polarity reversal of the neoplastic cells, so that the basal portion acquires secretory properties, facilitating the secretion capacity by neoplastic cells of substances responsible for stromal and vascular invasion, which gives the tumors greater potential for aggression.

\section{Metalloproteinases}

Metalloproteinases (MMPs) are proteins responsible for the breakdown of extracellular matrix both in normal physiological processes such as embryonic development, reproduction, and tissue remodeling, and in disease processes, such as arthritis and metastases. Metalloproteinases are divided into four groups: collagenases, stromelysins, gelatinases, and metalloproteinases. There are about 20 MMPs; their nomenclature is indicated by numbers such as MMP 1, -3, -8 and -14, which have collagenase activity, and they can be produced by tumor cells or fibroblasts and macrophages induced by the action of neoplastic cells. They act on the collagen molecules by cleaving the three different types of $\alpha$-chain in this protein. ${ }^{16}$

The first barrier encountered by a tumor cell is the basement membrane. To cross it, the neoplastic cells secrete type IV collagenase; when they reach the connective tissue, they begin to release collagenase types I and III. The greater the ability of neoplastic cells to produce such enzymes (belonging to the group of metalloproteinases), the greater is their invasiveness and metastatic potential. ${ }^{28}$

In breast carcinomas, expression of matrix metalloproteinase-13 (MMP-13, encoded by the MMP13 gene, located on chromosome 11q22.3) is found in peritumoral stromal cells and neoplastic cells; their expression was not identified in ductal epithelial cells in normal breast tissue. $^{28}$

Experimental studies have shown that MMP-13 could be associated with tumor progression. However, its applicability as an independent prognostic marker in breast carcinomas is still not clearly established. In a study by Zhang et al., ${ }^{29} \mathrm{MMP}-13$ was detected in the cytoplasm of cancer cells and in peritumoral stroma, both findings being correlated with lymph node involvement. MMP-13 expression was also correlated with the expression of Her $2 /$ neu. High expression levels of this protein in cancer cells were related to more aggressive tumor phenotypes and decreased survival. Nevertheless, its expression in fibroblasts was less significant in this study. Thus, the role of metalloproteinases, particularly MMP-13 expressed by tumor epithelial cells and fibroblasts, correlates with progression of mammary tumors, lymph node involvement, and reduced survival. ${ }^{29}$

Several studies have demonstrated the relationship between the expression of markers of invasiveness such as metalloproteinases, cell proliferation markers such as $\mathrm{Ki} 67$, and the role of claudins in poor prognosis and increased metastatic potential of breast tumors. ${ }^{4,22,30}$

\section{Discussion}

Carcinogenesis is a complex and multiphase process, dependent on genetic and epigenetic changes that culminate in the emergence of "immortalized" cell clones, which acquire a capacity to invade surrounding tissue and metastasize to distant organs. ${ }^{16}$ However, the development of cancer depends on factors other than just genetic or epigenetic changes in the affected cells. The tumor has cells positioned into the stroma in the tissue of origin, where there are defense cells whose function is to eliminate the abnormal clone. Despite the individualism of neoplastic cells, they interact with their peers through the extracellular matrix, and with stromal cells (fibroblasts and mast cells), innate defense cells and adaptive cells (dendritic cells, lymphocytes, macrophages, polymorphonuclear cells and eosinophils); this interaction involves sending and receiving more signals, and it is this exchange that results in making the environment permissive or not to the progression of cancer. Therefore, the stroma and its cells actively participate in the development of cancer. Mutations in 
stromal cells of many tumors are frequent, being already identified in pre-neoplastic processes. ${ }^{16}$

On the other hand, the ECM (extracellular medium) constitutes a barrier to tumor cells because it lodges and produces, after proteolysis, molecules that inhibit cellular proliferation and angiogenesis, also emitting antiproliferative and apoptosis-inhibiting signs by binding their components (collagen) with integrins. Thus, the progression of a malignancy occurs only if the stroma is permissive or becomes permissive due to signals produced by the neoplastic cells. ${ }^{31}$

Other stromal cells such as mast cells and leukocytes interfere with the process of carcinogenesis; mast cells release metalloproteinase-activating serine proteases, which are essential for the development of initial angiogenesis. Leukocytes, in turn, infiltrate the tumor stroma producing many growth factors (cytokines and chemo-cytokines), influencing matrix cells and tumor cells, being capable of destroying them. The development of the neoplasm, therefore, requires the tumor cells to get rid of the host's defense mechanisms.

Proinflammatory cytokines released in inflammation, especially in chronic inflammation, play an important role in angiogenesis, especially early angiogenesis, which ensures the survival of cancer cells and stimulates extracellular matrix degradation, favoring the migration of cancer cells. Chronic inflammation works favoring carcinogenesis due to the pro-oxidant environment it creates, with excess production of free radicals, an increased number of mutations and facilited genomic instability, conditions associated with neoplastic progression. ${ }^{16}$

Knowledge of the role of adhesion molecules in the carcinogenic process increases every year, with better understanding of the interaction between molecules and cell-stroma relationship in the process of invasion and metastasis. ${ }^{32}$ The loss of function or expression of E-cadherin in epithelial neoplasms has been considered as the main reason for breaking the close relationship between cells in epithelial tissues, leading to progression of a tumor to an invasive or metastatic state. ${ }^{33}$ On the other hand, the function of E-cadherins is absent in many epithelial tumors, due to mutational inactivation of E-cadherin and of catenins genes, and transcriptional repression and proteolysis of the extracellular domain, leading to the conclusion that these and other molecules show an important suppressive role in epithelial tumorigenesis, including metalloproteinases. P-cadherins, in turn, when displaying aberrant expression, correlate with breast carcinomas that display high histological grade, poor prognosis, and negative result for estrogen receptors, an important therapeutic target in breast cancer.
The lack of expression of certain molecules such as claudins is associated with a more aggressive phenotype that exhibits resistance to initial or adjuvant therapy often employed, and currently, this expression pattern led researchers to identify, within the molecular classification of breast tumors, a new subtype called "claudin low", whose biomolecular characteristics are associated with carcinomas that display narrow transition between epithelium and mesenchyme.

\section{Conclusion}

We note that the role of adhesion molecules is of paramount importance both in the activation of carcinogenesis and in the differentiation of mammary carcinoma subtypes, aiding in the diagnosis, prognosis and therapeutic choice in these tumors. Many of these molecules can and, in the future, will become therapeutic targets. Therefore, understanding the functions and interrelationships among these molecules is crucial to the pathologist, who often uses these factors as a resource to differentiate tumors and further classify them according to a molecular point of view, as well as daily routine.

\section{Resumo}

Moléculas de adesão no carcinoma mamário: um desafio ao patologista.

O papel das moléculas de adesão é de suma importância tanto na ativação da carcinogênese quanto na diferenciação dos subtipos de carcinomas mamários, auxiliando no diagnóstico, no prognóstico e na escolha terapêutica nessas neoplasias. Portanto, a compreensão das funções e das inter-relações entre essas moléculas é de suma importância para o patologista, que, muitas vezes, as utiliza como recurso na diferenciação dos tumores e, consequentemente, elas auxiliam em uma posterior classificação do ponto de vista molecular. O objetivo é descrever a aplicabilidade e as dificuldades encontradas pelo médico patologista no diagnóstico de carcinoma mamário, discutindo os marcadores de adesividade mais utilizados na rotina.

Palavras-chave: moléculas de adesão celular, moléculas de adesão juncional, neoplasias da mama.

\section{REFERENCES}

1. INCA (Instituto Nacional de Câncer). Available from: URL: http//www.inca. gov.br/conteúdo_view.asp?id=336-2010

2. Paredes J, Correia AL, Ribeiro AS, Milanezi F, Cameselle-Teijeiro J, Schmitt FC. Breast carcinomas that co-express E- and P-cadherin are associated 
with p120-cathenin cytoplasmatic localsation and poor patient survival. Journal Clin Pathol 2008;61:856-62.

3. Fanelli MA, Montt-Guevara M, Diblasi AM, Gago FE, Tello O, Cuello-Carríon $\mathrm{DF}$, et al. P-cadherin and beta-cathenin are useful prognostic markers in breast cancer patients; beta-cathenin interacts with heat shock protein Hsp27. Cell stress\&chaperones 2008;13: 207-20.

4. Prat A, Karginova O, Fan C, Perou M. Notch-associated expression profiles in basal-like and claudin-low breast cancer molecular subtypes. Journal of Clinical Oncology 2009; 27: 11017.

5. Kovács A, Dhillon J, Walker RA: Expression of P-cadherin, but not E-cadherin or $\mathrm{N}$-cadherin, relates to pathological and functional differentiation of breast carcinomas. Molecular Pathology 2003;56:318-22.

6. Gumbiner BM. Regulation of cadherin adhesive activity. J Cell Biol 2000; 148:399-404

7. Day ML, Zhao X, Vallosi CJ, Putzi M, Powell CT, Lin C, Day KC. E-cadherin mediates aggregation-dependent survival of prostate and mammary epithelial cell through the retinoblastoma cell cycle control pathway. J Biol Chem 1999;274:9656-64.

8. Yoshida R, Kimura N, Harada Y, Ohuchi N. The loss of E-cadherin, alphaand beta-catenin expression is associated with metastasis and poor prognosis in invasive breast cancer. Int J Oncol 2001.18: 513-20.

9. Kleer CG, van Golen KL, Braun T, Merajver SD. Persistent E-cadherin expression in inflammatory breast cancer. Modern Pathology 2001; 14:458-64.

10. Shimoyama Y, Hirohashi S, Hirano S, Nogushi M, Shimosato Y, Takeichi $\mathrm{M}$, Abe O. Cadherin cell-adhesion molecules in human epithelial tissues and carcinomas. Cancer Res 1989; 49:2128-33.

11. Rodrigues SRB, Yabiko M, Thomaz RB, Theodoro T, Alves B, Azzalis LA, et al. E-Cadherin, beta-catenin and HER2 expression in prostate cancer tissues with perineural invasion and their correlation with Gleason score: a preliminary study. African J Pharmacy and Pharmacology 2014; 8:194-198.

12. Mayer B, Johnson JP, Leitl F, Jauch KW, Seiss MM, Schildberg FW, Birchmeier W, Funke I. E-cadherin expression in primary and metastatic gastric cancer: down-regulation correlates with cellular dedifferentiation and glandular disintegration. Cancer Res 1993; 53:1690-95.

13. Dorudi S, Hanby AM, Poulsom R, Northover J, Hart IR. Level of expression of E-cadherin mRNA in colorectal cancer correlares with clinical outcome. Br J Cancer 1995;71:614-16.

14. Palacios J, Benito N, Pizarro A, Suarez A, Espada J, Cano A, Gamallo C. Anomalous expression of $\mathrm{P}$-cadherin in breast carcinoma. Correlation with E-cadherin expression and pathological features. Am J Pathol 1995;146:605-12.

15. Jiang WG, Hiscox S, Hallett MB, Horrobin DF, Scott C, Puntis MCA. Inhibition of invasion and motility of human colon cancer cells by gamma linolenic acid. Br J Cancer 1995;71:744-52.

16. Brasileiro Filho G. Distúrbios do crescimento e diferenciação celular: In Bogliolo patologia. 7.ed. Rio de Janeiro: Guanabara Koogan. 2006 p.181-204.

17. Kowalski P J, Mark RA, Kleer CG. E-cadherin expression in primary carcinomas of the breast and its distant metastasis. Breast Cancer Res 2003, 5:217-22.
18. Qureshi HS, Linden MD, Divine G. E-cadherin status in breast cancer correlates with histologic type but does not correlate with established prognostic parameters. Am J Clin Pathol 2006;125: 377-85

19. Gamallo C, Moreno-Bueno G, Sarrió D, Calero F, Hardisson D, Palacios J. The prognostic significance of P-cadherin in infiltrating ductal breast carcinoma. Modern Pathology 2001; 14:650-4.

20. Wu JC, Gregory CW, De Philip RM. P-cadherin and E-cadherin are co-expressed in MDCK cells. Biochem Biophys Res Commun 1993;195:1329-35.

21. Takahashi K, Suzuki K. Density-dependent inhibition of growth involves prevention of EGF receptor activation by E-cadherin-mediated cell-cell adhesion. Exp Cell Res 1996; 226:214-22.

22. Myal Y, Leygue E, Blanchard AA. Claudin 1 in breast tumorigenesis: revelation of a Possible Novel "claudin high" subset of breast cancers. Journal of Biomedicine and Biotechnology 2010; doi: 10,1155/2010/956897.

23. Rakha EA, Boyce RWG, Abd El Rehim D JFR, Kurien T, Green AR, Paish EC, Robertson JFR, Ellis IO. Expression of mucins (MUC1, MUC2, MUC3, MUC4, MUC5AC and MUC6) and their prognostic significance in human breast cancer. Modern Pathology 2005; 18:1295-304.

24. Luna-Moré S, Rius F, Weil B, Jimenez A, Bautista MD, Pérez-Mellado A. EMA: A differentiation antigen related to node metastatic capacity of breast associated carcinomas. Pathol Res Pract 2001;197:419-25.

25. Llano P, Cordoba A, Ariceta I, Beloqui R, Arrechea MA, Martinez-Peñuela JM Carcinoma micropapilar invasor de mama. Presentación de 6 casos. VII Congreso Virtual Hispanoamericano de Anatomia Patológica y I Congreso de preparaciones virtuales por internet 01-31 out. 2005. Available from: http:// www.conganat.org/7congreso/final/vistaImpresion.asp?id_trabajo=230.

26. Nassar H, Pansare V, Zhang H, Che M, Sakr W, Ali-Fehmi R, et al. Pathogenesis of invasive micropapillary carcinoma: role of MUC 1 glycoprotein. Modern Pathology 2004; 17:1045-105.

27. Pettinato G, Manivel CJ, Panico L, Sparano L, Petrella G. Invasive micropapillary carcinoma of the breast: clinicopathologic study of 62 cases of poorly recognized variant with highly aggressive behavior. Am J Clin Pathol 2004; 121:857-866.

28. Egeblad M. The role of matrix metalloproteinase 13 in breast cancer. Unversity of California, San Francisco; Postdoctoral Fellowship 2002 (Cycle VII).

29. Zhang B, Xuchen C, Yanxue L, Wenfeng C, Zhang F, Zhang S, et al. Tumorderived matrix metalloproteinase-13 (MMP-13) correlates with poor prognoses of invasive breast cancer. BMC Cancer 2008, 8:83.

30. Badve S, Dabbs,DJ, Schnitt SJ, Baehner FL, Decker T, Eusebi V, et al. Basallike and triple-negative breast cancers: a critical review with an enphasis on the implications for pathologists and oncologists. Modern Pathology 2011;24:157-67.

31. Kadara A, Tõkésa AM, Kulkaa J, Robert L. Extracellular matrix components in breast carcinomas $2002 ; 12: 243-57$

32. Sànchez LS, Vàzquez JMVH, Marure RL. Papel de las Caderinas en la metástasis. REB 2005; 24:97-103

33. Hajra KM, Fearson ER. Cadherin and Catenin alteration in Human Cancer. Genes Chomosomes Cancer 2002;34:255-268. 